Check for updates

Cite this: RSC Adv., 2019, 9, 25151

\title{
Improving the stability and ductility of polylactic acid via phosphite functional polysilsesquioxane
}

\author{
Ji Luo, ${ }^{a}$ Xin Meng, (D) *a Weiguang Gong, ${ }^{\text {b }}$ Zewen Jiang ${ }^{a}$ and Zhong Xin (D) a
}

To improve the stability and ductility of polylactic acid (PLA), chain extender or crosslinking agent of phosphite functional polysilsesquioxane (PPSQ) was synthesized by the reaction of phosphite group with the amino group of poly(amino-epoxy)silsesquioxane (PSQ). First, the reaction of PPSQ with PLA was characterized by molecular weight $\left(M_{w}\right)$ and melt mass flow rate (MFR) of PLA after melting reaction. The results showed a $6.6 \%$ increase in the $M_{w}$ of PLA and a $24.5 \%$ decrease in MFR value at the PPSQ loading content of 2 wt\% in PLA, indicating that PPSQ takes chain extension or crosslinking in PLA. Then, this result was further supported by the thermal stability improvement of PLA, which was testified by the increase of oxidative activation energy and the oxygen onset temperature (OOT) value. PPSQ improved the water resistance and mechanical properties of PLA. The hydrolysis rate decreased by $46.8 \%$, and the tensile strength and impact strength increased by $17.2 \%$ and $89.4 \%$. Taken together, these results indicate that the addition of PPSQ can produce the PLA with excellent thermal stability, hydrolytic stability and mechanical properties.

Received 27th April 2019

Accepted 5th August 2019

DOI: $10.1039 / c 9 r a 03147 b$

rsc.li/rsc-advances essential to produce PLA with improved thermal-oxidation stability and hydrolytic stability. ${ }^{20,21}$

Much work so far has contributed to overcome its disadvantages through chemical and physical modifications, including copolymers, ${ }^{22}$ blending with other polymers, ${ }^{23-29}$ additive controlling, as well as the combination of blending and additive controlling.

Of all the modification methods, additive modification is a simple and effective way to control the properties of PLA. Experimental evidences show that additive can improve the performance of polymer further through its interaction with polymer. For example, using melt reaction of PLA/PBAT blended with ADR compatibilizer, Wang et al. developed a high-strength and high-toughness PLA/PBAT blends. ${ }^{30}$ Battegazzore et al. used Joncryl ADR-4368 to prepare PLA and PHB copolymer-based cotton fabric bio-composites with promoted mechanical performances. In the composite, the epoxy groups of Joncryl ADR-4368 did not react with polyesters to restore or increase the original molecular weight of polyesters, but also reacted with the hydroxyl group in fabric, the polymer and the fabric were combined through ADR and the mechanical properties of composite was improved substantially. ${ }^{31}$

As far as the thermal property of PLA is concerned, the increase of molecular weight is beneficial. PLA with promoted stability can be obtained through the reaction between PLA and additive to form high molecular weight PLA. ${ }^{32}$ Regarding PLA, carboxyl and hydroxyl groups on both ends of molecules with high reactivity can react with compounds containing amino, ester and epoxy groups. ${ }^{33,34}$ The molecular weight of PLA can be increased through the reaction of PLA with the compounds

\footnotetext{
${ }^{a}$ Shanghai Key Laboratory of Multiphase Materials Chemical Engineering and Production Engineering Department, School of Chemical Engineering, East China University of Science and Technology, Shanghai, 200237, PR China. E-mail: mengxin@ecust.edu.cn

${ }^{b}$ Research and Development Center for Sports Materials, East China University of Science and Technology, Shanghai, 200237, China
}

\footnotetext{
increased through the reaction of PLA with the compounds
} 
having reactive groups, thereby improving its processing stability, thermal stability and mechanical properties.

In our previous work, we found that poly(amino-epoxy) silsesquioxane (PSQ) can increase the melting stability and mechanical properties of PLA through its reaction with PLA. ${ }^{35}$ However alkalinity found in the amino group could result in both the PLA degradation and a decrease in its the reaction activity. Reactivity of polysilsesquioxane can be improved if the amino group is linked via other functional groups. ${ }^{36}$ We ever studied the structure effect of phosphites on the chain extension in PLA and found that the P-O bond is stable and can improve the crystallization of PLA when there are bigger substituents around the $\mathrm{P}-\mathrm{O}$ bond. ${ }^{37,38}$ Based on the last research work, one type of novel additive was designed through the bonding of phosphite on PSQ. The amino group was functioned by phosphite group with bigger substitute around $\mathrm{P}-\mathrm{O}$ bond. The improvement of amino group can restrain the degradation of PLA. In addition, the group of $\mathrm{P}-\mathrm{O}$ bonded to PLA can increase the crystallization of PLA. ${ }^{39}$

In this work, the additive based PSQ (PPSQ) was prepared using PSQ and phosphite as raw material, and then grafted on the PLA through melt extrusion to prepare stability improved PLA (PPSQ-PLA). The resultant additive PPSQ was characterized by FT-IR and solid-state NMR. Furthermore, thermal oxidative stability, hydrolytic stability and mechanical properties of asprepared PPSQ-PLA were further discussed.

\section{Experimental}

\subsection{Materials}

PLA 2003D was purchased from Natureworks Company. Phosphorus trichloride $\left(\mathrm{PCl}_{3}\right)$ and anhydrous ethanol $\left(\mathrm{C}_{2} \mathrm{H}_{5} \mathrm{OH}\right)$ were provided by Sinopharm Chemical Reagent Co., Ltd. (Shanghai, China). 2,2'-Methylenebis(4,6-di-tert-butylphenol) was purchased from Nantong Advanced Chemical Co., Ltd. (Nantong, China). Toluene (TL) and triethylamine (TEA) were supplied by Shanghai Lingfeng Chemical Reagent Co., (Shanghai, China). Poly(amino-epoxy)silsesquioxane (PSQ) was synthesized in our laboratory according to previous research. ${ }^{35}$ All chemicals are A.R. grade and used as received.

\subsection{Synthesis of PPSQ}

The preparation of phosphite functional polysilsesquioxane (PPSQ) is depicted in Scheme 1. First, $0.025 \mathrm{~mol}$ of 2,2'-methylenebis(4,6-di-tert-butylphenol), $40 \mathrm{ml}$ of toluene and 1-2 $\mathrm{ml}$ of triethylamine were mixed in a $250 \mathrm{ml}$ four-necked flask with a nitrogen inlet reflux condenser device and mechanical stirrer. A mixture of phosphorus trichloride $(0.0325 \mathrm{~mol})$ and $20 \mathrm{ml}$ of toluene was slowly dropped into the flask at a temperature of 70$75{ }^{\circ} \mathrm{C}$ under nitrogen environment. After 0.5 hour of dripping, the temperature of the components gradually increased to $80-85{ }^{\circ} \mathrm{C}$ and the mixed solution continued to react for 3 hours and 2,2'methylenebis(4,6-di-tert-butylphenol)chlorophosphonite (A) was obtained. ${ }^{40}$ Then $15 \mathrm{~g}$ of polysilsesquioxane was added and $20 \mathrm{ml}$ of a toluene solution containing $5 \mathrm{ml}$ of triethylamine was added dropwise. At last, the reaction temperature was raised to 110-

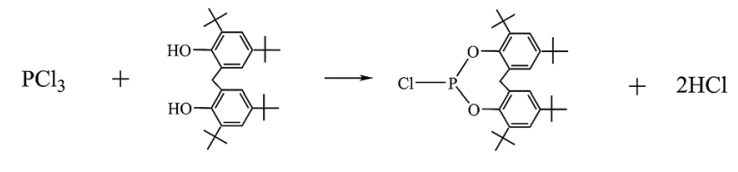

A

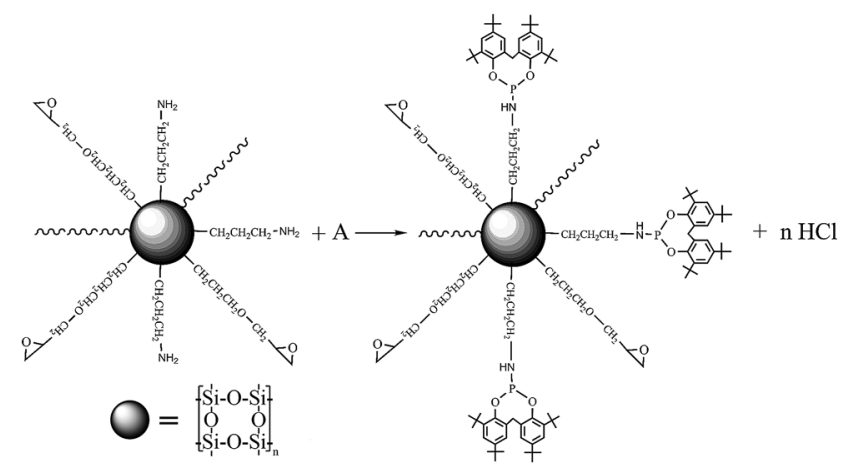

Scheme 1 Synthesis route of phosphite functionalized polysilsesquioxane (PPSQ).

$115{ }^{\circ} \mathrm{C}$ and the mixed solution was refluxed for $4-5 \mathrm{~h}$. After reaction, a pale yellow powder was collected by filtration and drying.

\subsection{Preparation of chain reacted PLA}

To avoid hydrolysis during processing, PLA was dried at $80^{\circ} \mathrm{C}$ in a vacuum oven for over $12 \mathrm{~h}$ prior to use. $2 \mathrm{wt} \%$ PSQ or PPSQ and PLA were blended at $180{ }^{\circ} \mathrm{C}$ in a Haake-Buchler batch mixer at a rotor speed of $80 \mathrm{rpm}$, as depicted in Scheme 2. After $10 \mathrm{~min}$ chain reacted PLA (PSQ-PLA, PPSQ-PLA) were obtained.

\subsection{Characterization}

FT-IR spectra characterization. Fourier transform infrared spectra (FT-IR) of PPSQ were measured by Thermo Fisher FT-IR spectrometer (iS10, FT-IR, Nicolet) in the range of 4000 to $400 \mathrm{~cm}^{-1}$ using a thin $\mathrm{KBr}$ pellet method.

NMR spectra characterization. ${ }^{29} \mathrm{Si}$ nuclear magnetic resonance measurements of PPSQ were performed by spectrometer

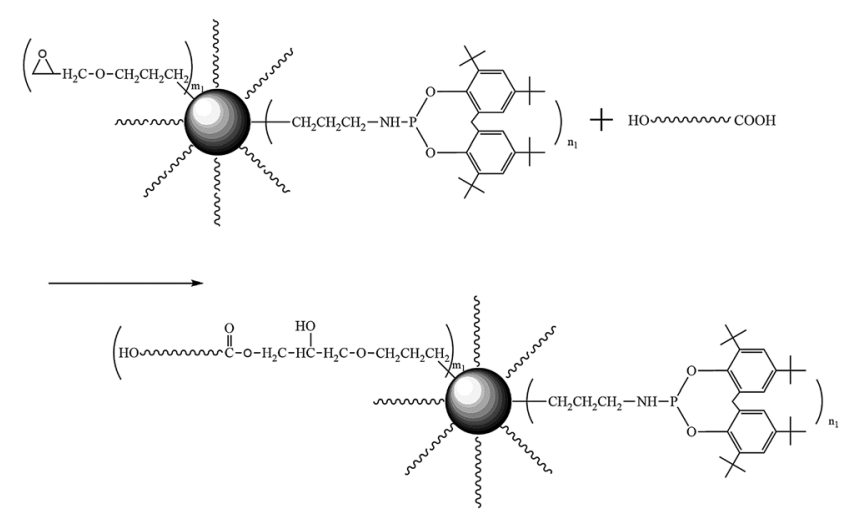

Scheme 2 Schematic diagram of preparation of PLA treated with PPSQ. 
(AVIII $400 \mathrm{MHz}$ WB, Bruker Inc.) with the ${ }^{29} \mathrm{Si}$ frequency of $79.49 \mathrm{MHz}$.

MFR measurement. The melt mass flow rate (MFR) was tested on MFR instrument (MI-4, Gottfert, Germany) according to ASTMD-1238. $10 \mathrm{~g}$ PLA sample was added into feed inlet at $190{ }^{\circ} \mathrm{C}$ with the load $2.16 \mathrm{~kg}$.

DSC analysis. The glass transition temperatures, cold crystallization temperature, melting temperatures and degree of crystallinity of PLA were measured on a TA Q-2000 differential scanning calorimeter (DSC). All DSC samples were heated to $200{ }^{\circ} \mathrm{C}$ at $20{ }^{\circ} \mathrm{C} \mathrm{min}^{-1}$ and held in the molten state for $5 \mathrm{~min}$, then cooled to $0{ }^{\circ} \mathrm{C}$ as quickly as possible, at last ramped the temperature from $0{ }^{\circ} \mathrm{C}$ to $200{ }^{\circ} \mathrm{C}$ at $10{ }^{\circ} \mathrm{C} \mathrm{min}^{-1}$. Degree of crystallinity $\left(X_{\mathrm{cc}}\right)$ after cold crystallization was calculated as follows:

$$
X_{\mathrm{cc}}(\%)=\frac{\Delta H_{\mathrm{cc}}}{\Delta H_{\mathrm{m}}^{100 \%} \times(1-w)} \times 100
$$

where $\Delta H_{\mathrm{m}}^{100 \%}$ is the theoretical melting enthalpy for PLA with $100 \%$ of crystallinity $\left(93.1 \mathrm{~J} \mathrm{~g}^{-1}\right) ; \Delta H_{\mathrm{cc}}$ is the crystallization enthalpy; $w$ is the mass fraction of the additive.

OOT analysis. The oxygen onset temperature (OOT) was obtained according to ASTM-3895. The samples were tested by ramping the temperature from $40{ }^{\circ} \mathrm{C}$ to $300{ }^{\circ} \mathrm{C}$ at different heating rates. The OOT values were determined at every inflection point in a heat flow $v s$. temperature plot.

GPC tests. Molecular weights of PLA was measured using Agilent GPC-50 gel permeation chromatography using chloroform as solvent at $35{ }^{\circ} \mathrm{C}$ under a flow rate of $1 \mathrm{ml} \mathrm{min}^{-1}$.

Hydrolytic degradation tests. Hydrolytic degradation of PLA was performed in deionized water at $95{ }^{\circ} \mathrm{C}$ for $24 \mathrm{~h}$. Samples were taken from water every $5 \mathrm{~h}$, then dried in a dryer for about $24 \mathrm{~h}$ to test weight loss. The weight loss rate was calculated according to the following formula:

$$
\text { Weight loss rate }(\%)=100 \% \times\left(W_{0}-W_{1}\right) / W_{0}
$$

where $W_{0}$ is the initial quality of the sample and $W_{1}$ is the quality of the sample after hydrolysis.

Water contact angle tests. The water contact angles of PLA were measured using an OCA20 optical goniometer. Ellipse fitting was used to calculate the water contact angle in the presence of a $2 \mu \mathrm{L}$ droplet, and the average value was obtained from seven different regions.

Mechanical performance tests. Tensile strength and elongation at break, flexural modulus, impact strength were tested according to ASTM standards D-638, D-790 and D-256, respectively. All samples were placed at room temperature for $48 \mathrm{~h}$ to eliminate internal stress before testing.

\section{Results and discussion}

\subsection{Characterization of PSQ and PPSQ}

Phosphite functional polysilsesquioxane (PPSQ) was prepared using PSQ and 2,2'-methylenebis(4,6-di-tert-butylphenol)chlorophosphonite as raw materials. Solid-state NMR spectra of PSQ and PPSQ are shown in Fig. 1. The results show that a main

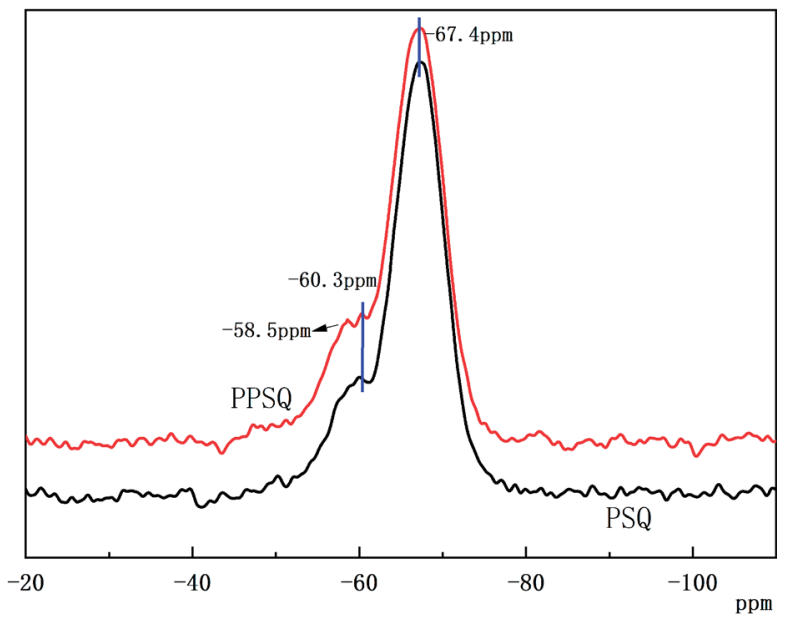

Fig. 1 Solid-state NMR spectra of PSQ and PPSQ.

strong peak at $-67.4 \mathrm{ppm}$ appeared in the NMR spectra of PSQ and PPSQ. This peak is between the main peaks of poly(aminoepoxy)silsesquioxane and epoxy polysilsesquioxane. It has been demonstrated that a strong peak in the range of 72-62 ppm due to the existence of Si-O-Si appears when polysilsesquioxane is fully condensed to form a network structure. ${ }^{35}$ The presence of acromion at high chemical shift is due to the different functional groups on the polysilsesquioxane. Both PSQ and PPSQ showed a weak acromion at $-60.3 \mathrm{ppm}$. It means that they contain same functional groups, i.e., the epoxy group. Furthermore, the acromion at $-\mathbf{5 8 . 5}$ ppm occurred only in PPSQ. It can indicate that the peak shift changed due to the functional effect of phosphite on polysilsesquioxane. These data confirm that phosphite was successfully grafted onto PSQ.

The infrared spectra of PSQ and PPSQ are shown in Fig. 2. Both of them exhibited a broad peak around $3400 \mathrm{~cm}^{-1}$, which is attributed to the absorptions of bending vibration of - $\mathrm{Si}-\mathrm{OH}-$ and the stretching vibration of $-\mathrm{NH}_{2}{ }^{36}$ The peaks at 2941 and $2872 \mathrm{~cm}^{-1}$ related to the vibration of $\mathrm{C}-\mathrm{H}$ in $\mathrm{CH}_{2}$ group were illustrated in the two curves. ${ }^{41}$ The absorptions bands at 1030 and $1115 \mathrm{~cm}^{-1}$ are assigned to the $\mathrm{Si}-\mathrm{O}-\mathrm{Si}$ stretching vibration.

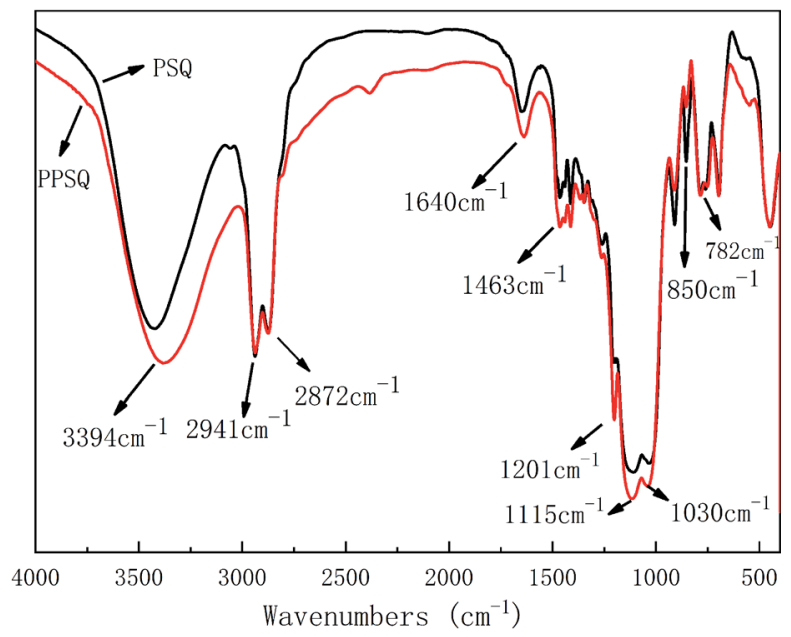

Fig. 2 The FT-IR curves of PSQ and PPSQ. 
Table 1 Molecular weight of chain reacted PLA

\begin{tabular}{lll}
\hline Samples & $M_{\mathrm{w}}\left(\mathrm{kg} \mathrm{mol}^{-1}\right)$ & MFR $\left(\mathrm{g} 10 \mathrm{~min}^{-1}\right)$ \\
\hline Virgin-PLA & $198.6 \pm 3.5$ & 4.9 \\
PSQ-PLA & $206.4 \pm 2.8$ & 4.6 \\
PPSQ-PLA & $213.0 \pm 3.1$ & 3.7
\end{tabular}

The peaks around $1030 \mathrm{~cm}^{-1}$ and $1115 \mathrm{~cm}^{-1}$ indicate that the PSQ has a cage structure and a ladder or layered structure, respectively. The peak at $782 \mathrm{~cm}^{-1}$ of $\mathrm{Si}-\mathrm{C}$ bond stretching vibration peak existed in the spectra of both PSQ and PPSQ. ${ }^{36,41,42}$ The rocking vibration absorption of primary amine at $850 \mathrm{~cm}^{-1}$ disappeared in PPSQ, which indicates that the amino group reacted with phosphite.

\subsection{Molecular weight of chain reacted PLA}

Molecular weights of PSQ-PLA and PPSQ-PLA represent that additives react with PLA successfully. As can be seen from Table 1, the $M_{\mathrm{w}}$ of PLA after the reaction with PSQ and PPSQ increased slightly compared with virgin PLA. The molecular weight of PSQ-PLA and PPSQ-PLA sample were $206.4 \mathrm{~kg} \mathrm{~mol}^{-1}$ and 213.0 $\mathrm{kg} \mathrm{mol}^{-1}$, respectively, which indicates that chain segment of PLA is lengthened by the reaction with additive.
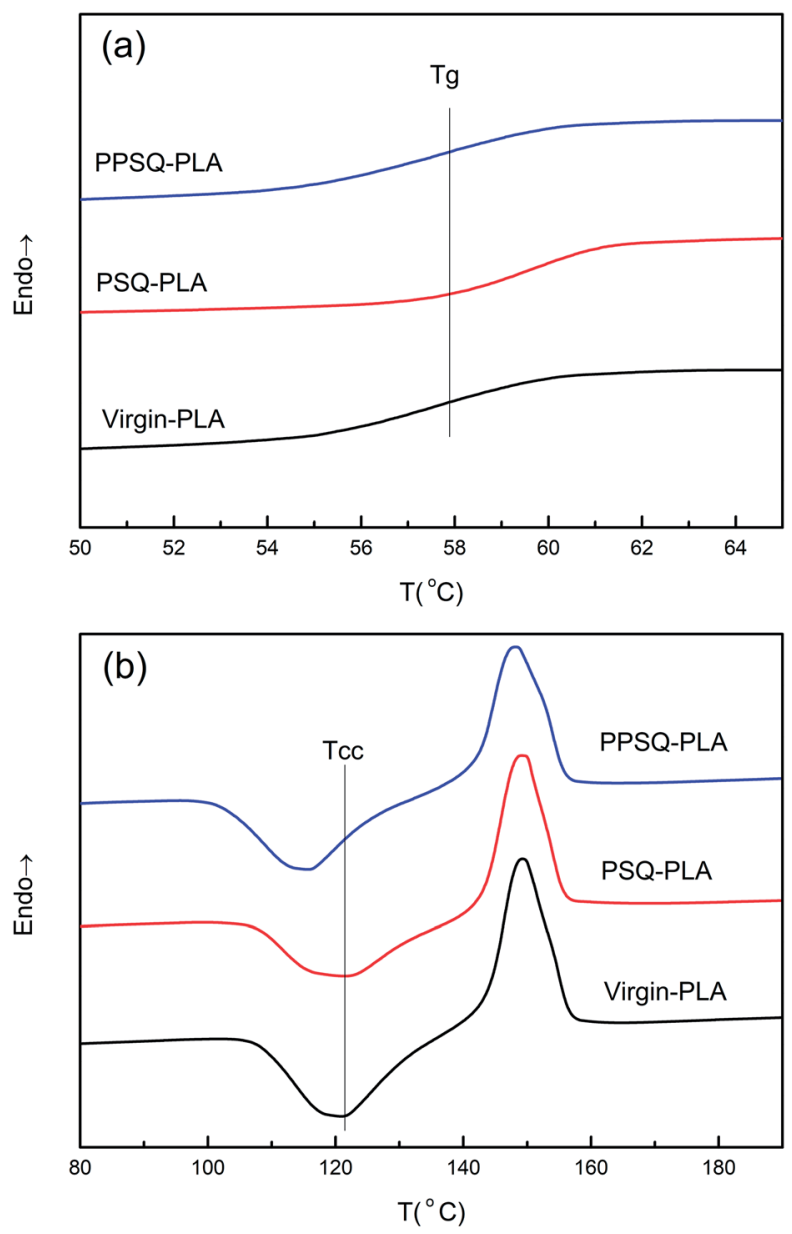

Fig. 3 The melting curve of virgin-PLA, PSQ-PLA and PPSQ-PLA.
Likewise, melt mass flow rate (MFR) determined by molecular weight and molecular structure. High molecular weight and branching can lead to a decrease in MFR. ${ }^{\mathbf{4 3 4} 4}$ As shown in Table 1, however, 2 wt $\%$ PSQ showed only very limited effect on MFR of chain reacted PLA due to the amino group. When phosphite was grafted onto PSQ, PPSQ-PLA was a minimum of $3.7 \mathrm{~g} 10 \mathrm{~min}^{-1}$, which indicates that PPSQ can act as an effective chain extender or crosslinking agent of PLA.

\subsection{Crystallization behavior of chain reacted PLA}

It is very essential to study the effect of the reaction of additive with PLA on the crystallization behaviour of PLA due to its slow crystallization rate. ${ }^{45-48}$ The thermal properties of virgin PLA, PSQ-PLA and PPSQ-PLA were analyzed by DSC. The second DSC heating curves of different PLA samples are displayed in Fig. 3.

All data from DSC are summarized in Table 2. Compared with virgin-PLA, the $T_{\mathrm{cc}}$ of PSQ-PLA increased slightly. However, the $T_{\mathrm{cc}}$ of PPSQ-PLA dropped to $115.7^{\circ} \mathrm{C}$, which is related to the plasticization of PPSQ in PLA. The grafting of phosphite onto PSQ can take plasticization in PLA, ${ }^{37}$ so PPSQ makes the $T_{\mathrm{g}}$ and $T_{\text {cc }}$ of PPSQ-PLA decrease. Meanwhile, the $X_{\text {cc }}$ of PPSQ-PLA increased from $16.2 \%$ to $20.5 \%$. These results can also be attributed to the plasticization of PPSQ, resulting in PLA chains with better mobility and crystallinity at higher molecular weight. All these results indicate that PPSQ-PLA crystallizes more easily and faster even though its molecular weight is increased.

Table 2 Cold crystallization temperature $\left(T_{c c}\right)$ and crystallinity degree after cold crystallization $\left(X_{c c}\right)$ of virgin-PLA, PSQ-PLA and PPSQ-PLA

\begin{tabular}{lcccc}
\hline Samples & $T_{\mathrm{g}} /{ }^{\circ} \mathrm{C}$ & $T_{\mathrm{cc}} /{ }^{\circ} \mathrm{C}$ & $X_{\mathrm{cc}} / \%$ & $\Delta H_{\mathrm{cc}} / \mathrm{J} \mathrm{g}^{-1}$ \\
\hline Virgin-PLA & 57.8 & 121.2 & 16.2 & 15.1 \\
PSQ-PLA & 58.7 & 121.6 & 18.0 & 16.4 \\
PPSQ-PLA & 57.8 & 115.7 & 20.5 & 18.7
\end{tabular}

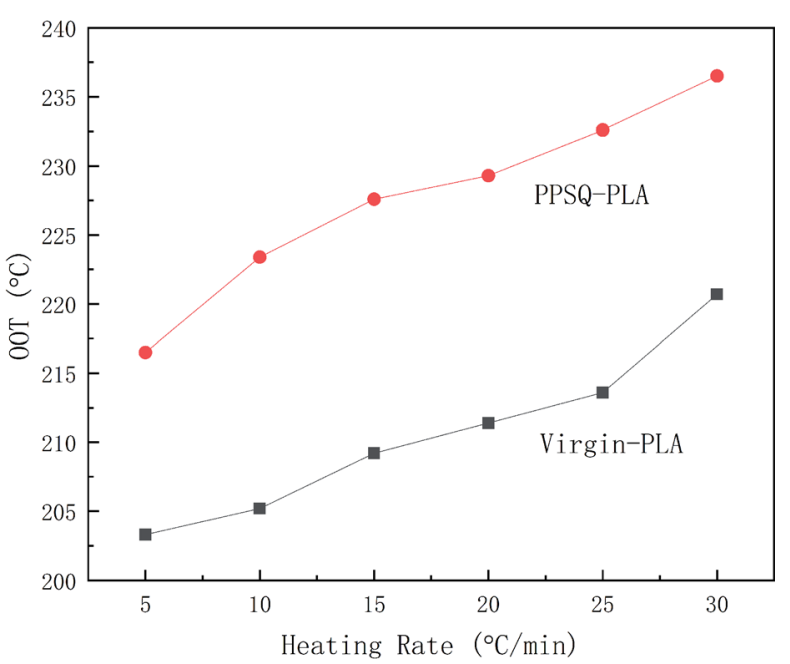

Fig. 4 The OOT values of virgin-PLA and PPSQ-PLA at different heating rates. 


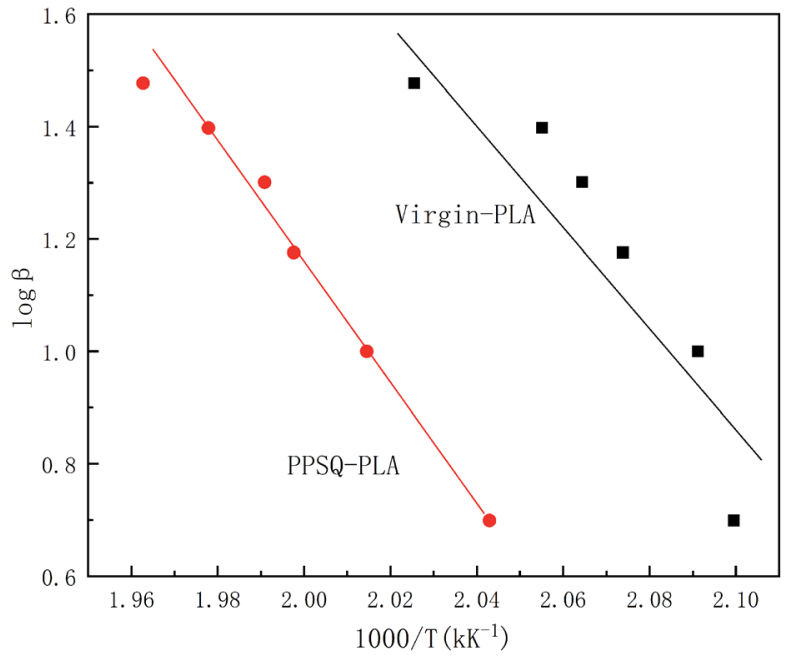

Fig. 5 The curves fitting of $\log \beta$ vs. 1/T with Ozawa method.

\subsection{Thermal oxidative stability of PPSQ-PLA}

Thermal oxidative degradation is a major cause of degradation of PLA. Therefore, it is necessary to study the thermal oxidation stability of PPSQ-PLA. The oxygen onset temperature (OOT) was obtained at different heating rates in an atmosphere of oxygen.

Fig. 4 shows that the OOT values of PPSQ-PLA increased by about $16{ }^{\circ} \mathrm{C}$ at the same heating rate compared with virgin-PLA. This indicates that PPSQ-PLA has better thermal oxidation stability than virgin-PLA due to the stabilization of silicon for PLA and the increase of molecular weight of PPSQ-PLA.

Table 3 Activation energy and slope of lines fitted by Ozawa and Kissinger equations

\begin{tabular}{lrllll}
\hline & \multicolumn{2}{l}{ Ozawa parameter } & & \multicolumn{2}{l}{ Kissinger parameter } \\
\cline { 2 - 3 } Samples & \multicolumn{1}{l}{ Slope } & $E / \mathrm{kJ} \mathrm{mol}^{-1}$ & & Slope & $E / \mathrm{kJ} \mathrm{mol}^{-1}$ \\
\hline Virgin-PLA & 9005.7 & 174.9 & & 21.1 & 175.4 \\
PPSQ-PLA & 10308.4 & 187.6 & & 22.5 & 187.1
\end{tabular}

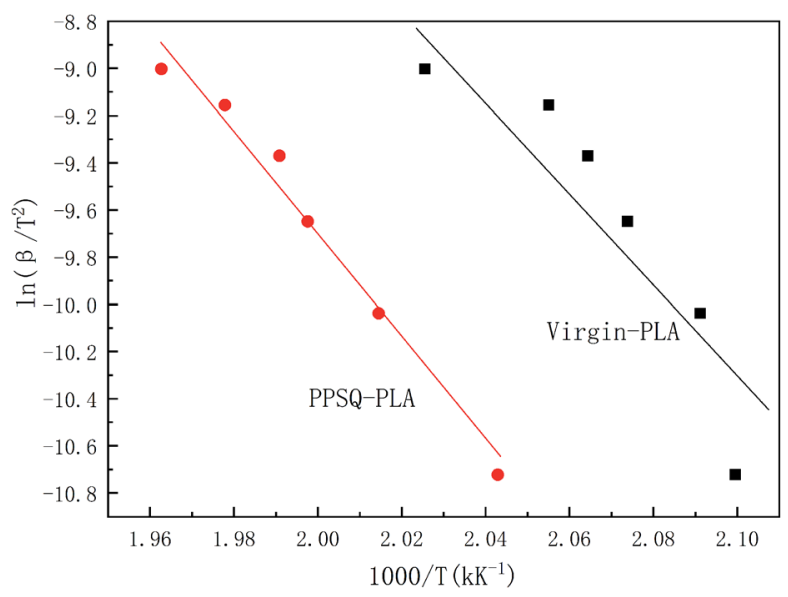

Fig. 6 The curves fitting of $\ln \left(\beta / T^{2}\right)$ vs. $1 / T$ with Kissinger method.

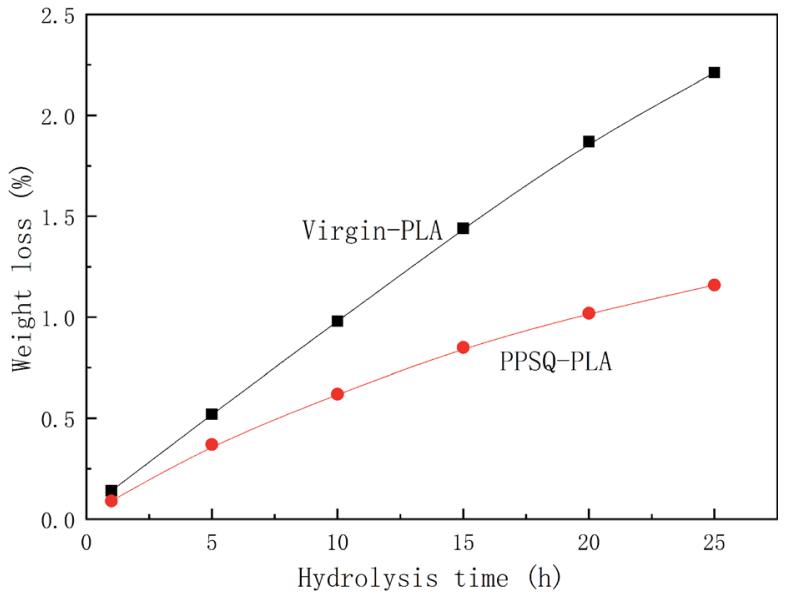

Fig. 7 Weigh loss of virgin-PLA and PPSQ-PLA at different hydrolysis time.

To study the effect of the reaction between PLA and PPSQ on the oxidative degradation mechanism of PLA, the kinetic parameters of degradation were calculated using Ozawa's and Kissinger's methods, respectively. ${ }^{49}$

According to Ozawa's theory, an exothermic reaction can be considered as a single step process and the conversion at the maximum conversion rate is invariant with the heating rate. Therefore, there is a linear relationship between the logarithm of heating rate, $\log \beta$ and the reciprocal of the absolute temperature, $T^{-1}$, as shown in eqn (2-1).

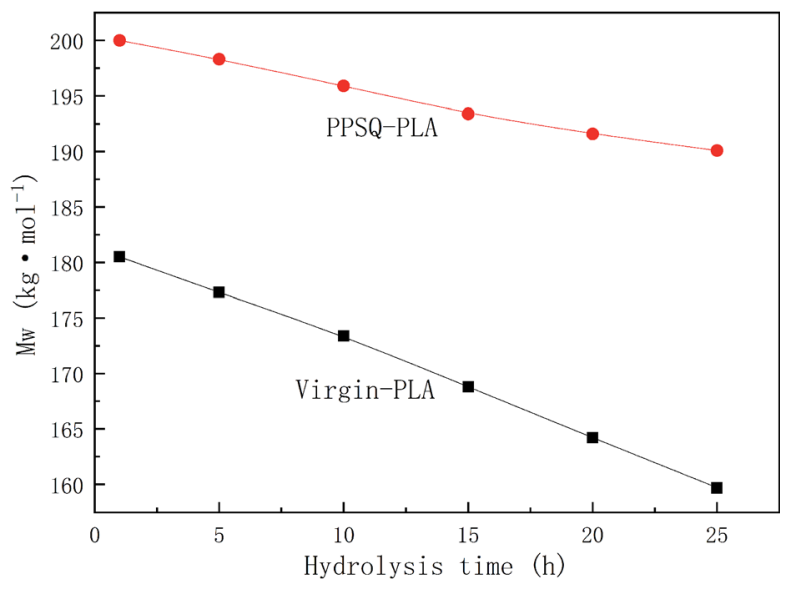

Fig. 8 Molecular weight of virgin-PLA and PPSQ-PLA at different hydrolysis time.
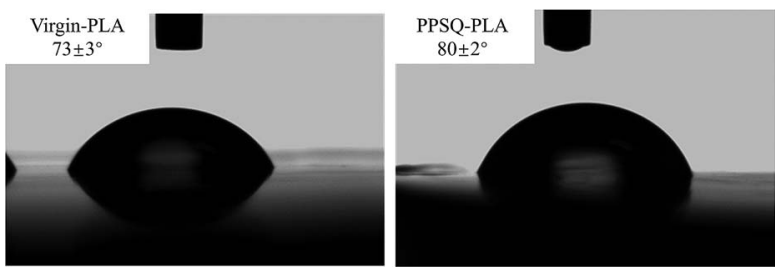

Fig. 9 Water contact angle of virgin-PLA and PPSQ-PLA. 
Table 4 Mechanical properties of virgin-PLA and PPSQ-PLA

\begin{tabular}{lllll}
\hline Samples & Impact strength $\left(\mathrm{J} \mathrm{m}^{-1}\right)$ & Flexural modulus $(\mathrm{MPa})$ & Tensile strength (MPa) & Elongation at break $(\%)$ \\
\hline Virgin-PLA & $26 \pm 1$ & $2507 \pm 15$ & $47 \pm 1$ & 4.1 \\
PPSQ-PLA & $50 \pm 1$ & $2570 \pm 25$ & $55 \pm 1$ & 5.0
\end{tabular}

$$
\begin{gathered}
\log \beta=a T^{-1}+b \\
E / R=\mathrm{d} \ln \left(\beta / T^{2}\right) /[\mathrm{d} \ln 1 / T]
\end{gathered}
$$

where parameter $a$ represents the slope of the linear equation and is equal to $-0.4567 E / R$ and $b$ is a constant. Based on Fig. 4, the curve of $\log \beta v$ s. $T^{-1}$ is obtained in Fig. 5 , and the oxidation activation energy $(E)$ can be calculated, as shown in Table 3 .

Furthermore, according to Kissinger's method, kinetic parameters were calculated using eqn (2-2). Based on Fig. 4, the plots of $\ln \left(\beta / T^{2}\right)$ vs. $1 / T$ are shown in Fig. 6. A good linear relationship existed between $\ln \left(\beta / T^{2}\right)$ and $1 / T$. The slopes of curves can be obtained from Fig. 6 and the results are shown in Table 3, too.

As seen in Table 3, the results of activation energies of oxidation obtained by Ozawa's and Kissinger's methods were very similar. Therefore, both methods can be used to study the oxidation degradation kinetics of PLA. The results show that the activation energy value of oxidation of PPSQ-PLA increased by 7.3\% compared with that of PLA, which indicates that the reaction between PLA and PPSQ improves the oxidation stability of virgin-PLA by increasing the activation energy of degradation in the molten state.

\subsection{Hydrolytic stability of PPSQ-PLA}

Hydrolysis process will generate large amounts of water-soluble monomer and oligomer lactic acid, which can reduce the service life of PLA. Fig. 7 shows weight loss of virgin-PLA and PPSQ-PLA samples as a function of hydrolysis time.

With the increase of hydrolysis time, the weight loss rate of virgin-PLA and PPSQ-PLA increased gradually, but the weight loss rate of virgin-PLA was significantly higher than that of PPSQ-PLA. When the hydrolysis time reached $25 \mathrm{~h}$, the weight loss rate of PPSQ-PLA showed a trend of equilibrium, whereas the weight loss rate of virgin-PLA did not show the same trend. Therefore, the addition of PPSQ can promote the hydrolysis resistance ability of PLA.

As shown in Fig. 8, the molecular weight of virgin-PLA and PPSQ-PLA decreased continuously. However, the slope of the molecular weight change of virgin-PLA was significantly higher than that of virgin-PLA, which indicates that the addition of PPSQ can improve the hydrolysis resistance of PLA. This result is consistent with the change of PLA weight loss rate with hydrolysis time.

To further confirm the reasons for the improvement of PLA hydrolysis resistance after the reaction with PPSQ, water contact angles were tested, as shown in Fig. 9. The results show that the water contact angle of PLA increased from $73^{\circ}$ to $80^{\circ}$ when PPSQ was added to PLA. PPSQ contains epoxy group reacting with carboxyl and hydroxyl group of PLA, which improves the hydrophobicity of PLA and decreases hydrolysis rate.

\subsection{Mechanical properties of chain reacted PLA}

To reveal the effect of the reaction between PPSQ and PLA on the mechanical properties of PLA, mechanical properties of PPSQ-PLA and virgin-PLA were investigated and the results are shown in Table 4.

The flexural modulus of PPSQ-PLA increased from $2507 \mathrm{MPa}$ to $2570 \mathrm{MPa}$, which indicates PPSQ hardly effects flexural modulus of PLA. ${ }^{50}$ The tensile strength increased from $47 \mathrm{MPa}$ to $55 \mathrm{MPa}$ (increased by $17.2 \%$ ) and the elongation at break increased from $4.1 \%$ to $5.0 \%$ (increased by $0.9 \%$ ). The impact strength increased from $26 \mathrm{~J} \mathrm{~m}^{-1}$ to $50 \mathrm{~J} \mathrm{~m}^{-1}$ (increased by $89.4 \%$ ), which is related to the effect of polysilsesquioxane. The $\mathrm{Si}-\mathrm{O}-\mathrm{Si}$ bond of the polysilsesquioxane molecule is long and easy to rotate, making $\mathrm{Si}-\mathrm{O}-\mathrm{Si}$ a flexible chain. ${ }^{51}$ At the same time, as the free ends of PLA chains were bound in the chemical reaction with epoxy groups, the stress concentrations decreased. ${ }^{50}$ Therefore, the addition of polysilsesquioxane to PLA can improve the fracture toughness of PLA without sacrificing its stiffness.

\section{Conclusion}

A novel additive PPSQ was synthesized by the reaction of phosphite group with the amino group of poly(amino-epoxy)silsesquioxane (PSQ) and was successfully grafted onto PLA. First, the higher $M_{\mathrm{w}}$ and lower cold crystallization temperature of chain reacted PLA were obtained, which increased by $6.6 \%$ and decreased by $24.5 \%$, respectively. Then, the oxidative degradation of PLA was characterized using oxygen onset temperature (OOT) and activation energy value of oxidation. The results show that when PPSQ was added in PLA, the activation energy value of oxidation and the oxygen onset temperature value increased by $7.3 \%$ and $16{ }^{\circ} \mathrm{C}$, respectively, which means PPSQ takes effective stabilization in the oxidation of PLA. Furthermore, the chain reacted PLA showed better water resistance and mechanical properties compared to PLA, i.e. the hydrolysis rate decreased by $46.8 \%$, and the tensile strength and impact strength increased by $17.2 \%$ and $89.4 \%$. This work presents a novel strategy for improving the stability and ductility of PLA.

\section{Conflicts of interest}

There are no conflicts to declare.

\section{Acknowledgements}

We are grateful for the financial support of the National Natural Science Funds of China (Grant No. 21576086). 


\section{References}

1 S. Lambert and M. Wagner, Chem. Soc. Rev., 2017, 46, 68556871.

2 P. Bordes, E. Pollet and L. Avérous, Prog. Polym. Sci., 2009, 34, 125-155.

3 P. V. A. Bergo, R. A. Carvalho, P. J. A. Sobral, R. M. C. dos Santos, F. B. R. da Silva, J. M. Prison, J. Solorza-Feria and A. Bittante, Packag. Technol. Sci., 2008, 21, 85-89.

4 H. M. Shaikh, K. V. Pandare, G. Nair and A. J. Varma, Carbohydr. Polym., 2009, 76, 23-29.

5 T. Mekonnen, P. Mussone, H. Khalil and D. Bressler, J. Mater. Chem. A, 2013, 1, 13379.

6 M. Rabnawaz, I. Wyman, R. Auras and S. Cheng, Green Chem., 2017, 19, 4737-4753.

7 J. Lunt, Polym. Degrad. Stab., 1998, 59, 145-152.

8 G.-Q. Chen and M. Patel, Chem. Rev., 2011, 112, 2082-2099.

9 B. Gyarmati and B. Pukánszky, Eur. Polym. J., 2017, 93, 612617.

10 P. Tamás-Bényei, T. Tábi and J. Kovacs, eXPRESS Polym. Lett., 2013, 7, 107-119.

11 K. Bocz, B. Szolnoki, A. Marosi, T. Tábi, M. WladykaPrzybylak and G. Marosi, Polym. Degrad. Stab., 2014, 106, 63-73.

12 R. Drumright, P. R. Gruber and D. E. Henton, Adv. Mater., 2000, 12, 1841-1846.

13 S. Bocchini, K. Fukushima, A. D. Blasio, A. Fina, A. Frache and F. Geobaldo, Biomacromolecules, 2010, 11, 2919-2926.

14 P. Liu, G. Yang and H. Shao, Eur. Polym. J., 2017, 93, 815-821. 15 S. Vanit, A. Sane, R. Yoksan and T. Jinkarn, Packag. Technol. Sci., 2018, 31, 61-69.

16 M. R. Snowdon, F. Wu, A. K. Mohanty and M. Misra, RSC Adv., 2019, 9, 6752-6761.

17 I. H. Kim and Y. Gyu Jeong, J. Polym. Sci., Part B: Polym. Phys., 2010, 48, 850-858.

18 Y. Li, Z. Qiang, X. Chen and J. Ren, RSC Adv., 2019, 9, 31283139.

19 J. R. Rocca-Smith, O. Whyte, C.-H. Brachais, D. Champion, F. Piasente, E. Marcuzzo, A. Sensidoni, F. Debeaufort and T. Karbowiak, ACS Sustainable Chem. Eng., 2017, 5, 27512762.

20 L. T. Lim, R. Auras and M. Rubino, Prog. Polym. Sci., 2008, 33, 820-852.

21 H.-J. Lin, S.-R. Liu, L.-J. Han, X.-M. Wang, Y.-J. Bian and L.-S. Dong, Polym. Degrad. Stab., 2013, 98, 1389-1396.

22 C. Fang, X. Wang, X. Chen and Z. Wang, Polym. Chem., 2019, 10, 3610-3620.

23 Y. Li, C. Han, J. Bian, L. Han, L. Dong and G. Gao, Polym. Compos., 2012, 33, 1719-1727.

24 N. Liu, X.-G. Chen, H.-J. Park, C.-G. Liu, C.-S. Liu, X.-H. Meng and L.-J. Yu, Carbohydr. Polym., 2006, 64, 60-65.

25 A. Argoud, L. Trouillet-Fonti, S. Ceccia and P. Sotta, Eur. Polym. J., 2014, 50, 177-189.
26 Y. Ohya, S. Maruhashi and T. Ouchi, Macromol. Chem. Phys., 1998, 199, 2017-2022.

27 A. J. Nijenhuis, E. Colstee, D. W. Grijpma and A. J. Pennings, Polymer, 1996, 37, 5849-5857.

28 R. Khankrua, S. Pivsa-Art, H. Hiroyuki and S. Suttiruengwong, Polym. Degrad. Stab., 2014, 108, 232-240.

29 K. Behera, V. Sivanjineyulu, Y.-H. Chang and F.-C. Chiu, Polym. Degrad. Stab., 2018, 154, 248-260.

30 X. Wang, S. Peng, H. Chen, X. Yu and X. Zhao, Composites, Part B, 2019, 173, 107028.

31 D. Battegazzore, A. Frache, T. Abt and M. L. Maspoch, Composites, Part B, 2018, 148, 188-197.

32 S. Ghosh, J. C. Viana, R. L. Reis and J. F. Mano, Mater. Sci. Eng., A, 2008, 490, 81-89.

33 N. Najafi, M. C. Heuzey, P. J. Carreau and P. M. WoodAdams, Polym. Degrad. Stab., 2012, 97, 554-565.

34 F. Li, Z. Liu, X. Cheng, S. Chen, D. Liu, R. Sun, J. Chen and X. Liu, Eur. Polym. J., 2006, 42, 1349-1356.

35 T. Han, Z. Xin, Y. Shi, S. Zhao, X. Meng, H. Xu and S. Zhou, J. Appl. Polym. Sci., 2015, 132, DOI: 10.1002/app.41977.

36 Y. Wang, R. Qu, F. Pan, X. Jia, C. Sun, C. Ji, Y. Zhang, K. An and Y. Mu, Chem. Eng. J., 2017, 317, 187-203.

37 X. Meng, G. Shi, C. Wu, W. Chen, Z. Xin, Y. Shi and Y. Sheng, Polym. Degrad. Stab., 2016, 124, 112-118.

38 X. Meng, G. Shi, W. Chen, C. Wu, Z. Xin, T. Han and Y. Shi, Polym. Degrad. Stab., 2015, 120, 283-289.

39 Y. Qian, P. Wei, P. Jiang, J. Hao and J. Du, Composites, Part B, 2013, 45, 1541-1547.

40 X. Meng, Z. Jiang, Z. Xin, W. Chen, Y. Sheng and W. Chushi, J. Appl. Polym. Sci., 2017, 134, DOI: 10.1002/app.44696.

41 M. Lu, P. Liu, S. Zhang, W. Yuan, S. Ding, F. Wang, Y. Ding and M. Yang, Polym. Degrad. Stab., 2018, 154, 137-148.

42 J. Rubio, M. A. Mazo, A. Martín-Ilana and A. Tamayo, Bol. Soc. Esp. Ceram. Vidrio, 2018, 57, 160-168.

43 M. Harada, K. Iida, K. Okamoto, H. Hayashi and K. Hirano, Polym. Eng. Sci., 2008, 48, 1359-1368.

44 Q. Zhou, H. Xu, A. Wang, Z. Ma, H. Li, L. Zhang and Y. Hu, J. Appl. Polym. Sci., 2017, 134, DOI: 10.1002/app.44704.

45 N. Ji, G. Hu, J. Li and J. Ren, RSC Adv., 2019, 9, 6221-6227.

46 S. Barrau, C. Vanmansart, M. Moreau, A. Addad, G. Stoclet, J. M. Lefebvre and R. Seguela, Macromolecules, 2011, 44, 6496-6502.

47 N. Dintcheva, S. Al-Malaika, E. Morici and R. Arrigo, J. Appl. Polym. Sci., 2017, 134, DOI: 10.1002/app.44974.

48 T. Miyata and T. Masuko, Polymer, 1998, 39, 5515-5521.

49 Y.-C. Chiu, F.-Y. Liu, C.-C. M. Ma, I. C. Chou, L. Riang, C.-L. Chiang and J.-C. Yang, Thermochim. Acta, 2008, 473, 7-13.

50 A. Jaszkiewicz, A. Bledzki, R. van der Meer, P. Franciszczak and A. Meljon, Polym. Bull., 2014, 71, 1675-1690.

51 X. Dong, Z. Zhang, L. Yuan, G. Liang and A. Gu, RSC Adv., 2016, 6, 40962-40969. 